\title{
Routine Histopathology for Resected Gallbladder Specimens: Outcomes and Cost-benefit Analysis at a District General Hospital, Retrospective Cohort Study
}

\author{
Aboutaleb Esam*, Saleh Fatima, Pore Naresh, Raje Durgesh, Mitsopoulos Grigos, Sheth Hemant \\ General Surgery Department, Ealing Hospital, London North West Trust, London, UK \\ Email address: \\ e.aboutaleb@nhs.net (A. Esam) \\ ${ }^{*}$ Corresponding author \\ To cite this article: \\ Aboutaleb Esam, Saleh Fatima, Pore Naresh, Raje Durgesh, Mitsopoulos Grigos, Sheth Hemant. Routine Histopathology for Resected \\ Gallbladder Specimens: Outcomes and Cost-benefit Analysis at a District General Hospital, Retrospective Cohort Study. Science Research. \\ Vol. 9, No. 4, 2021, pp. 51-54. doi: 10.11648/j.sr.20210904.12
}

Received: June 21, 2021; Accepted: July 2, 2021; Published: July 15, 2021

\begin{abstract}
Routine histopathological assessment of resected gallbladder specimens is a common practice in the UK. However, the incidence of incidental gallbladder cancer is low and there is a debate over whether selective histopathology is more appropriate. Here we aim to identify the incidence of malignant and pre-malignant disease upon routine histological analysis of gallbladder specimens in Ealing hospital. We conducted a retrospective analysis of gallbladder histopathology reports was performed for all patients undergoing cholecystectomy at Ealing Hospital between June 2011 and December 2018. Demographic information, operative findings, pathology results, staging, treatment and outcome information were collected for each case of malignant or pre-malignant disease. The total financial cost of histopathological analysis of resected specimens was calculated. A total of 1,612 patients underwent cholecystectomy with histopathological assessment of the resected specimen. The majority of specimens showed chronic cholecystitis $71.3 \%$. Acute cholecystitis $28.1 \%$. Gall bladder polyps found in two patients $0.12 \%$. Low grade dysplasia was identified in three patients $0.19 \%$ while high grade dysplasia was identified in two patients $0.12 \%$, and malignant disease was reported in three patients $0.19 \%$, two patients had stage 2 and one had stage 3 gall bladder cancer. All cases of malignant disease were identified by the surgeon intra-operatively on gross inspection. The cost of routine histopathological analysis was $£ 128$ per patient. The incidence of pre-malignant or malignant gallbladder disease after cholecystectomy is rare. A selective approach to histopathological assessment, based on patient age, clinical presentation and intra-operative findings, will provide a financial and labour cost saving.
\end{abstract}

Keywords: Gallbladder, Histopathology, Cost

\section{Introduction}

Cholecystectomy is a common surgical procedure, with approximately 70,000 patients undergoing operative treatment for predominantly benign disease of the gallbladder annually in the United Kingdom (UK) [1]. The routine histopathological analysis of each resected specimen, to identify subclinical pre-malignant or malignant disease, is widespread practice within the National Health Service and throughout the world.

Incidental gallbladder cancer identified on resected specimens is rare, with reported rates ranging from $0.15 \%$ to $2.8 \%$ global $[1,2,11,12,3-10]$. Carcinoma of the gallbladder has a poor prognosis, particularly when presenting late [7]. The incidental discovery of a gallbladder malignancy represents $30-70 \%$ of all new diagnoses, and associates with improved outcomes when the patient undergoes further surgery and increased overall survival $[6,13,14]$. Routine analysis of gallbladder specimens is advocated to identify incidental gallbladder cancer in its subclinical or early stage $[1,2]$. However, there remains a debate as to whether routine histopathological analysis of resected specimens is warranted $[5,8,15]$. The rarity of incidental cancer, the 
financial cost of histopathological analysis, and the labor burden on pathology laboratories all support the argument for a selective assessment [15].

The aim of this study was to identify the incidence of malignant and pre-malignant disease upon routine histological analysis of gallbladder specimens in a UK district general hospital. The total monetary cost of histopathological analysis per patient was calculated.

\section{Materials and Methods}

The histopathology reports of all patients undergoing cholecystectomy between June 2011 and December 2018 at Ealing Hospital (West London, UK) were reviewed retrospectively (Research registry 5843). All patients were treated for presumed benign disease with laparoscopic, laparoscopic converted to open, or open surgery. Specimens were inspected macroscopically by the operating surgeon during the procedure. All resected gallbladders were sent to the pathology lab for histopathological assessment. Specimens with premalignant or malignant gallbladder lesions were identified. Patient demographic information, operative findings, staging, treatment and outcome information were collected for each case.

The total financial cost of routine histopathological assessment of gallbladder specimens was calculated by our histopathology lab.

Statistical analysis was undertaken in Excel (Microsoft, USA). Data was collected using a predetermined proforma. The research and ethics committee at Ealing Hospital approved the study and patients' anonymity was preserved at all time. The work has been reported in line with the STEOCSS criteria [23].

\section{Results}

Over the 7.5-year study period 1,612 patents underwent cholecystectomy and routine gallbladder histopathology (table 1). Mean age was $41.3( \pm 1.9)$ years and $64 \%$ of patients were female.

The majority of specimens were reported as benign disease (99.4\%), Chronic cholecystitis was $71.3 \%$ while acute cholecystitis $28.1 \%$. Gall bladder polyps found in $0.12 \%$. Low and high grade dysplasia occurred in $0.19 \%$ and $(0.12 \%)$ respectively (table 2 ).

Malignant lesions were detected in three patients $(0.19 \%$; table 2). All cases of malignant gallbladder disease were suspected by the operating surgeon intraoperatively on macroscopic assessment of the specimen. Tumours were staged as stage 2 in two patients and one stage 3 .

The cost of routine gallbladder histopathological analysis at Ealing Hospital was calculated as $£ 128.00$ per patient. This included tissue processing and examination by a consultant pathologist. The estimated total cost per annum of routine gallbladder histology is $£ 27,511.47$.
Table 1. Summary of histopathological findings and demographic features.

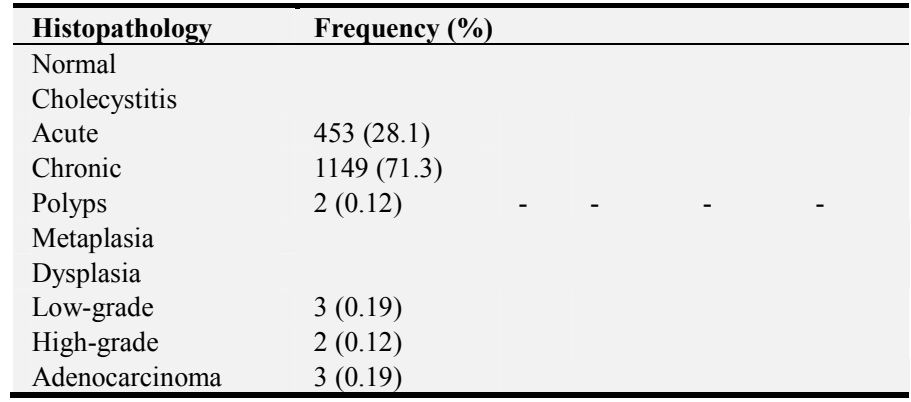

Table 2. Summary of pre-malignant and malignant gallbladder histopathology specimens.

\begin{tabular}{llll}
\hline Patient & Age Sex & Gallbladder histology & \\
\hline 1 & $55 \mathrm{~F}$ & Low grade dysplasia & \\
2 & $62 \mathrm{M}$ & Low grade dysplasia & \\
3 & $56 \mathrm{~F}$ & Low grade dysplasia & \\
4 & $61 \mathrm{~F}$ & High grade dysplasia & \\
5 & $64 \mathrm{~F}$ & High grade dysplasia & \\
6 & $59 \mathrm{~F}$ & CANCER & Stage 2 \\
7 & $67 \mathrm{~F}$ & CANCER & Stage 2 \\
8 & $62 \mathrm{M}$ & CANCER & Stage 3 \\
\hline
\end{tabular}

\section{Discussion}

In this study of 1,612 cholecystectomies, the rate of incidental malignant and pre-malignant gallbladder disease identified in resected specimens was $0.19 \%$ and $0.31 \%$ respectively. The majority of pathology was benign (99.4\%). The financial cost of routine histopathological analysis was $£ 128.00$ per patient; equivalent to approximately $£ 27,511.47$ per annum.

Our cohort has high percentage of acute cholecystitis as we run an active hot cholecystectomy program. This may explain low percentage of GB polyps and cancer despite of high percentage of Asian ethnicity group in our cohort. Gallbladder cancer is associated with poor prognosis and an overall five-year survival rate of only $5-13 \%[14,16]$. The risk factors of gallbladder cancer are porcelain gallbladder, gallbladder polyp, primary sclerosis cholangitis, chronic infection, congenital biliary cyst or abnormal pancreaticobiliary duct junction [17-20]. The incidental discovery of malignancy in resected gallbladder specimens contributes the majority of gallbladder cancer diagnoses [14, 21]. The remaining $30-50 \%$ of patients typically present much later in the disease course, with signs and symptoms of hepatobiliary malignancy. At this point the disease is often less amenable to curative surgery $[14,21]$. As such, incidentally discovered gallbladder cancer is associated with increased overall survival, and therefore many clinicians advocate the histopathological analysis of all resected specimens to diagnose and treat malignancy early [14]. Radiological images of our cohort of patients prior surgery did not show suspicious features of malignancy.

However, the financial and labour costs from the histopathological assessment of each resected gallbladder are not insignificant [9]. Some clinicians have argued that a more selective assessment of specimens, taking into account certain risk factors, clinical features and intra-operative 
findings, may continue to identify malignant and premalignant disease at increased cost-effectiveness [5, 9].

Similar rates of incidental gallbladder malignancy to this study have been found in other UK centers. Patel and colleagues analysed the specimens of 4,027 patients at a tertiary hepatobiliary center [1]. Rates of adenocarcinoma were $0.15 \%$ and dysplasia $1.4 \%$. Similarly, Emmett and colleagues reported an adenocarcinoma rate of $0.25 \%$ in a cohort of 4,776 cholecystectomies [9]. In contrast, studies in high risk locations, such as India and Pakistan, report higher rates of adenocarcinoma $(0.44-2.8 \%)[2,7]$. This variation in the rate of gallbladder malignancy with location and ethnicity potentially highlights the need to change practice based on the patient demographic. Selective histopathological analysis may be suitable in populations with a lower risk of gallstone disease.

All three gallbladder malignancies in this study were identified on macroscopic inspection during the operation by the surgeon. Similar findings have been reported in other studies, where all cases of malignancy were identified intraoperatively [8, 9]. Macroscopic abnormalities on inspection included wall thickening, discrete masses, necrotic tissues, fistulation and perforation [9]. In a systematic review of the literature, Jamal and colleagues observed that $92 \%$ of gallbladder cancers demonstrated macroscopic abnormalities intra-operatively [22]. The authors suggest that macroscopically normal specimens from low risk patients (European, aged under 60 years) may not require formal histopathology. Other authors suggested that GB cancer can be found in normal looking gall bladder specimens [1]. Our study may be weakened by high number of hot cholecystectomies which might affected the percentage of incidental GB cancer.

\section{Conclusion}

Selective histopathological assessment of resected gallbladders may fail to identify malignant and pre-malignant pathology at a time when it is more amenable to treatment. However, due to the rarity of pathology, and financial and labor costs, it may be appropriate to identify a subset of patients for histopathological assessment in whom the risk of malignant disease is high. Histopathology should be undertaken in all patients who are female, are aged over 60 years, have risk factors for malignant gallbladder disease, have suspicious preoperative imaging or have suspicious clinical features. All resected gallbladders should undergo macroscopic inspection intra-operatively by the surgeon and abnormal specimens should be sent for formal histopathological analysis.

\section{References}

[1] Patel K, Dajani K, Iype S, Chatzizacharias NA, Vickramarajah $\mathrm{S}$, Singh $\mathrm{P}$, et al. Incidental non-benign gallbladder histopathology after cholecystectomy in an United Kingdom population: Need for routine histological analysis? World $J$ Gastrointest Surg. United States; 2016 Oct; 8: 685-692.
[2] Siddiqui FG, Memon AA, Abro AH, Sasoli NA, Ahmad L. Routine histopathology of gallbladder after elective cholecystectomy for gallstones: waste of resources or a justified act? BMC Surg. England; 2013 Jul; 13: 26.

[3] Basak F, Hasbahceci M, Canbak T, Sisik A, Acar A, Yucel M, et al. Incidental findings during routine pathological evaluation of gallbladder specimens: review of 1,747 elective laparoscopic cholecystectomy cases. Ann $R$ Coll Surg Engl. England; 2016 Apr; 98: 280-283.

[4] Dincel O, Goksu M, Hatipoglu HS. Importance of routine histopathological examination of a gallbladder surgical specimen: Unexpected gallbladder cancer. J Cancer Res Ther. India; 2018; 14: 1325-1329.

[5] Wrenn SM, Callas PW, Abu-Jaish W. Histopathological examination of specimen following cholecystectomy: Are we accepting resect and discard? Surg Endosc. Germany; 2017 Feb; 31: 586-593.

[6] Lundgren L, Muszynska C, Ros A, Persson G, Gimm O, Valter L, et al. Are Incidental Gallbladder Cancers Missed with a Selective Approach of Gallbladder Histology at Cholecystectomy? World J Surg. United States; 2018 Apr; 42: 1092-1099.

[7] Kalita D, Pant L, Singh S, Jain G, Kudesia M, Gupta K, et al. Impact of routine histopathological examination of gall bladder specimens on early detection of malignancy - a study of 4,115 cholecystectomy specimens. Asian Pac J Cancer Prev. Thailand; 2013; 14: 3315-3318.

[8] Koppatz H, Nordin A, Scheinin T, Sallinen V. The risk of incidental gallbladder cancer is negligible in macroscopically normal cholecystectomy specimens. HPB (Oxford). England; 2018 May; 20: 456-461.

[9] Emmett CD, Barrett P, Gilliam AD, Mitchell AI. Routine versus selective histological examination after cholecystectomy to exclude incidental gallbladder carcinoma. Ann R Coll Surg Engl. England; 2015 Oct; 97: 526-529.

[10] Dorobisz T, Dorobisz K, Chabowski M, Pawlowski W, Janczak D, Patrzalek D, et al. Incidental gallbladder cancer after cholecystectomy: 1990 to 2014. Onco Targets Ther. New Zealand; 2016; 9: 4913-4916.

[11] Choi KS, Choi SB, Park P, Kim WB, Choi SY. Clinical characteristics of incidental or unsuspected gallbladder cancers diagnosed during or after cholecystectomy: a systematic review and meta-analysis. World J Gastroenterol. United States; 2015 Jan; 21: 1315-1323.

[12] Hayes BD, Muldoon C. Seek and ye shall find: the importance of careful macroscopic examination and thorough sampling in 2522 cholecystectomy specimens. Ann Diagn Pathol. United States; 2014 Jun; 18: 181-186.

[13] Hari DM, Howard JH, Leung AM, Chui CG, Sim M-S, Bilchik AJ. A 21-year analysis of stage I gallbladder carcinoma: is cholecystectomy alone adequate? HPB (Oxford). England; 2013 Jan; 15: 40-48.

[14] Ethun CG, Le N, Lopez-Aguiar AG, Pawlik TM, Poultsides G, Tran $\mathrm{T}$, et al. Pathologic and Prognostic Implications of Incidental versus Nonincidental Gallbladder Cancer: A 10Institution Study from the United States Extrahepatic Biliary Malignancy Consortium. Am Surg. United States; 2017 Jul; 83: 679-686. 
[15] Soreide K, Guest R V, Harrison EM, Kendall TJ, Garden OJ, Wigmore SJ. Systematic review of management of incidental gallbladder cancer after cholecystectomy. Br J Surg. England; 2019 Jan; 106: 32-45.

[16] Cubertafond P, Gainant A, Cucchiaro G. Surgical treatment of 724 carcinomas of the gallbladder. Results of the French Surgical Association Survey. Ann Surg. United States; 1994 Mar; 219: 275-280.

[17] Wistuba II, Miquel JF, Gazdar AF, Albores-Saavedra J. Gallbladder adenomas have molecular abnormalities different from those present in gallbladder carcinomas. Hum Pathol. 1999; 30 (1): 21 .

[18] Said K, Glaumann H, Bergquist A. Gallbladder disease in patients with primary sclerosing cholangitis. J Hepatol. 2008; 48 (4): 598.

[19] Hundal R, Shaffer EA. Gallbladder cancer: epidemiology and outcome. Clin Epidemiol. 2014; 6: 99. Epub 2014 Mar 7
[20] 2Chijiiwa K, Kimura H, Tanaka M. Malignant potential of the gallbladder in patients with anomalous pancreaticobiliary ductal junction. The difference in risk between patients with and without choledochal cyst. Int Surg. 1995; 80 (1): 61.

[21] Butte JM, Matsuo K, Gonen M, D’Angelica MI, Waugh E, Allen PJ, et al. Gallbladder cancer: differences in presentation, surgical treatment, and survival in patients treated at centers in three countries. J Am Coll Surg. United States; 2011 Jan; 212: $50-61$.

[22] Jamal K, Ratansingham K, Siddique M, Nehra D. Routine histological analysis of a macroscopically normal gallbladder-a review of the literature. Int J Surg. England; 2014; 12: 958962.

[23] Agha R, Abdall-Razak A, Crossley E, Dowlut N, Iosifidis C and Mathew G, for the STROCSS Group. The STROCSS 2019 Guideline: Strenthening the Reporting of Cohort Studies in Surgery. International Journal of Surgery 2019; 72: 156-165. 